\title{
Original Article \\ Primary central nervous system lymphomas: Indian experience, and review of literature
}

\author{
Paul TR, Challa S, Tandon A, Panigrahi MK'ㄹ, Purohit AK ${ }^{1}$ \\ Department of Pathology, 'Department of Neurosurgery, Nizam's Institute of Medical Sciences, \\ Punjagutta, Hyderabad - 500 082, Andhra Pradesh, India.
}

Correspondence to: Dr. Tara Roshni Paul, E-mail: troshnip@yahoo.co.in

\begin{abstract}
Primary central nervous system lymphomas (PCNSLs) are a rare form of non-Hodgkin's lymphoma which arise within and remain confined primarily to the central nervous system (CNS). They generally account for $1-2 \%$ of all primary brain tumors and are reported to be on the rise due to the Acquired Immune Deficiency Syndrome (AIDS) epidemic. AIMS AND OBJECTIVES: To study the clinicopathological and immunophenotypic characteristics of PCNSLs and look for any differences in PCNSLs reported in India from those in other countries. MATERIALS AND METHODS: All cases of PCNSLs between January 1998 and December 2006 were reviewed. Presence of lymphadenopathy, organomegaly and bone marrow study was done to exclude the possibility of secondary involvement by lymphoma. The diagnosis was confirmed by histopathology with Hematoxylin and Eosin and reticulin stains. Immunohistochemistry (IHC) with leucocyte common antigen (LCA), CD 20 and CD 3 was performed on available blocks. The immune status was evaluated by clinical examination and human immunodeficiency virus (HIV) serology (since 1996). RESULTS: In a 19-year study period, there were 56 patients of PCNSLs, accounting for $1.07 \%$ of all intracranial neoplasms. The patients ranged from 10-75 years of age with a median age of 42 years. Barring one patient who was HIV positive, all the others were immunocompetent. All cases were diffuse large cell lymphomas on histopathology. IHC with LCA and CD 20 revealed positivity in $100 \%$ and $86.4 \%$ cases respectively. There was a single case of CD 3 positive T-cell lymphoma. In the present study, PCNSLs occurred in young immunocompetent patients and majority were diffuse large B cell lymphomas.
\end{abstract}

Key words: Diffuse lymphoma, immunohistochemistry, PCNSLs

\section{Introduction}

Primary central nervous system lymphomas (PCN SLs) are a rare form of extranodal non-H odgkin's lymphoma, that typically remain confined primarily to the central nervous system and involve the brain, leptomeninges, spinal cord or eye. ${ }^{[1]} \mathrm{H}$ istorically, the first reported PCNSL was by Bailey in 1929,, ${ }^{[2]}$ when he used the term 'perithelial sarcoma'. Other terms that have been used are perivascular sarcoma, adventitial sarcoma, malignant reticuloendotheliosis, reticulum cell sarcoma, microglioma. It was much later that PCNSLs were recognized as neoplasia distinct from glial tumors by immunophenotyping and the lymphoid nature of the lesion was established.
Reports from the west ${ }^{[3]}$ indicated that there was a three-fold increase in incidence of PCN SL s between 1973 and 1984. The H uman Immunodeficiency Virus (HIV) was the main factor responsible for the rise. H owever, there was also a rise of PCNSLs in the immunocompetent. This increasing incidence could have been due to improved investigative modalities (stereotactic brain biopsies of deep-seated lesions), greater clinical and neuropathological awareness, widespread availability of immunohistochemistry and increase in the number of immunosuppressed patients, who have an increased risk of developing PCNSLS. $L$ ater reports ${ }^{[4]}$ suggested that the annual incidence of PCNSL appeared to be stabilizing or in fact declining slightly. Studies published from India ${ }^{[5,6]}$ indicate that there has been no increase in the incidence of PCN SL 
and that they tend to occur a decade earlier than the west.

The purpose of this study was to determine the clinicopathological profile of patients diagnosed with PCNSLs at a tertiary care centre, to determine the hospital-based incidence and look for any differences in PCN SLS occurring in India from those in other countries.

\section{Materials and Methods}

All cases of histologically proven PCNSLs, diagnosed at a tertiary care center from January 1988 to December 2006, were included in the study. The complete clinical and imageologic details were obtained from the patient records. D etails about lymphadenopathy, organomegaly and bone marrow study were obtained to exclude the possiblity of secondary involvement by a systemic lymphoma. The histopathology of each case was reviewed with $\mathrm{H}$ ematoxylin and $\mathrm{E} o$ sin and reticulin stain. Immunohistochemistry (IHC) with leucocyte common antigen (LCA), CD 20 (B cell marker), and CD 3 ( $T$ cell marker) was performed on available formalin-fixed, paraffin embedded blocks using the standard AvidinBiotin Complex technique. The antibodies used were monoclonal mouse Anti Human leucocyte common antibody CD 45, monoclonal mouse Anti H uman CD $20 \mathrm{cy}$ and polyclonal rabbit Anti $\mathrm{H}$ uman CD 3.These were supplied by DAKO / Dakocytomation company (the suppliers being J. Mitra and sons, Chennai, Tamil $\mathrm{N}$ adu, India; imported from Denmark.) The immune status was evaluated by clinical examination and H IV serology reports were available in all patients after 1996.

\section{Results}

\section{Incidence}

During the study period, there were 5208 intracranial neoplasms, of which 56 were PCNSLs, giving a percentage of $1.07 \%$. Table 1 shows the year-wise distribution of cases along with the incidence and confidence limits. There has been a fairly constant incidence of PCNSLs from 1988 to 2006.

\section{Clinical features}

The age of the patients ranged from 11 to 75 years of age with a median age of 42 years and a male to female ratio of 1.5: 1. Of the 56 patients, only one was HIV positive and the rest were immunocompetent. The age /gender distribution is depicted in Table 2. The clinical features with which the patients presented with are shown in Table 3.
The most common presenting symptom was headache.

The site of involvement is shown in Table 4.

$M$ ajority of the lesions occurred in the supratentorial

\begin{tabular}{|c|c|c|c|c|}
\hline Year & CNS tumors & PCNSLs & Percentage & $\begin{array}{l}95 \% \text { confidence } \\
\text { limits }^{\star}\end{array}$ \\
\hline 1988 & 122 & 2 & 1.6 & 0.002 to 0.058 \\
\hline 1989 & 148 & 1 & 0.6 & 0.000 to 0.037 \\
\hline 1990 & 191 & 1 & 0.5 & 0.000 to 0.028 \\
\hline 1991 & 274 & 1 & 0.3 & 0.000 to 0.020 \\
\hline 1992 & 289 & 2 & 0.7 & 0.000 to 0.024 \\
\hline 1993 & 230 & Nil & 0.0 & 0.000 to 0.016 \\
\hline 1994 & 284 & Nil & 0.0 & 0.000 to 0.013 \\
\hline 1995 & 121 & Nil & 0.0 & 0.000 to 0.030 \\
\hline 1996 & 301 & 1 & 0.3 & 0.000 to 0.018 \\
\hline 1997 & 283 & 2 & 0.7 & 0.000 to 0.025 \\
\hline 1998 & 205 & 3 & 1.4 & 0.000 to 0.042 \\
\hline 1999 & 398 & 8 & 2.0 & 0.008 to 0.039 \\
\hline 2000 & 274 & Nil & 0.0 & 0.000 to 0.013 \\
\hline 2001 & 197 & 2 & 1.0 & 0.001 to 0.036 \\
\hline 2002 & 302 & 4 & 1.3 & 0.003 to 0.033 \\
\hline 2003 & 230 & 6 & 2.5 & 0.009 to 0.055 \\
\hline 2004 & 455 & 6 & 1.3 & 0.004 to 0.013 \\
\hline 2005 & 423 & 9 & 2.1 & 0.009 to 0.040 \\
\hline 2006 & 473 & 8 & 1.6 & 0.007 to 0.033 \\
\hline Total & 5208 & 56 & 1.07 & 0.008 to 0.014 \\
\hline
\end{tabular}

*Lower and upper range of $95 \%$ confidence limits calculated by exact (Binomial) method, CNS: Central nervous system, PCNSLs: Primary central nervous system lymphomas

Table 2: Age/gender distribution of patients with PCNSLs ( $\mathrm{n}=56$ )

\begin{tabular}{lcc}
\hline Age range in years & Male & Female \\
\hline $0-9$ & Nil & Nil \\
\hline $10-19$ & 6 & 1 \\
\hline $20-29$ & 4 & 2 \\
\hline $30-39$ & 7 & 3 \\
\hline $40-49$ & 7 & 9 \\
\hline $50-59$ & 5 & 4 \\
\hline $60-69$ & 3 & 2 \\
\hline $70-79$ & 2 & 1 \\
\hline
\end{tabular}

One patient was HIV positive, the rest were immunocompetent, PCNSLs: Primary central nervous system lymphomas 
Table 3: Clinical presentation of patients with PCNSLs ( $n=56)$

\begin{tabular}{ll} 
Clinical features & Number of cases \\
\hline Headache & 40 \\
\hline Weakness/paresis & 24 \\
\hline Vomiting & 27 \\
\hline Seizures & 11 \\
\hline Upper motor neuron palsy & 7 \\
\hline Behavioral changes & 7 \\
\hline Altered sensorium & 5 \\
\hline Diminished vision & 4 \\
\hline Gait disturbances & 6 \\
\hline Speech defects & 2 \\
\hline Deafness & 2 \\
\hline Loss of smell & 1 \\
\hline Loss of taste & 1 \\
\hline PCNSLs: Primary central nervous system lymphomas & \\
\hline
\end{tabular}

region, with multiple lesions being common and frontal lobe being most frequently involved.

I mageologic details were available in 36 of 50 patients. In 20 of these patients, CT scans were available and in another 16 cases, MRI scans were also available. The CT scans showed isodense to hyperdense lesions in majority of the patients and four patients had hypodense lesions. The M R Is revealed lesions which were hypointense on $T_{1}$ and hyperintense on $T_{2}$ with three patients having ring-enhancing lesions.

All the patients were assessed for evidence of a systemic lymphoma and the search did not yield a primary. Most of the patients had a bone marrow evaluation as part of a staging work-up, but these were normal.

After diagnosis, most of the patients were referred for chemotherapy and/or radiotherapy. They were subsequently lost to follow-up.

\section{Pathology}

Gross pathology: M ost of the biopsy specimens were resected biopsy specimens, consisting of multiple greywhite, or grey-tan soft tissue bits, with few showing hemorrhagic and necrotic areas. A few cases had stereotactic biopsies.

\section{Histopathology}

All the cases showed a non-Hodgkin's Iymphoma arranged in a diffuse pattern. Of these, 55 cases were reported as diffuse large cell Iymphoma [Figure 1] and
Table 4: Sites of involvement by PCNSLs ( $n=56$ )

\begin{tabular}{ll}
\hline Site & Number of cases \\
\hline Multiple & 12 \\
\hline Frontal & 18 \\
\hline Parietal & 16 \\
\hline Temporal & 8 \\
\hline Thalamus & 8 \\
\hline Corpus callosum & 4 \\
\hline Occipital & 2 \\
\hline Cerebellum & 2 \\
\hline Periventricular & 2 \\
\hline Capsulo ganglionic segment & 2 \\
\hline Cerebello pontine angle & 1 \\
\hline Meningeal & 1 \\
\hline Third ventricle & 1 \\
\hline PCNSLs: Primary central nervous system lymphomas
\end{tabular}

Table 5: Immunohistochemistry results

\begin{tabular}{lc}
\hline Immunohistochemistry marker & Result \\
\hline Lymphoma panel & - \\
\hline Leucocyte common antigen (LCA) & Done in 56 cases \\
\hline Strongly positive & $54 / 56$ cases $(96 \%)$ \\
\hline Weakly positive & $2 / 56$ cases $(4 \%)$ \\
\hline CD 20 (B - cell marker) & Done in 37 cases \\
\hline Strongly positive & $27 / 37$ cases $(72.9 \%)$ \\
\hline Weakly positive & $5 / 37$ cases $(13.5 \%)$ \\
\hline Negative & $5 / 37$ cases $(13.5 \%)$ \\
\hline CD 3 (T - cell marker) & Done in 18 cases \\
\hline Positive & $1 / 18$ cases \\
\hline Negative & $14 / 18$ cases \\
\hline Reactive $T-$ cell + ve & $3 / 18$ cases \\
\hline
\end{tabular}

one as lymphoblastic lymphoma. Angiocentric pattern was noted in 48 cases [Figure 2]. Splaying of reticulin fibres around blood vessels was seen in 28 cases. $\mathrm{N}$ ecrosis, reactive gliosis and brain infiltration was seen in 17, 16 and 13 cases respectively. The lesion was admixed with inflammatory cells and histiocytes in five cases. There were two cases of recurrent PCNSLs, which showed post-therapy changes in the form of stromal collagenization and calcification.

\section{Immunohistochemistry}

The immunohistochemical results are depicted in Table 5. 


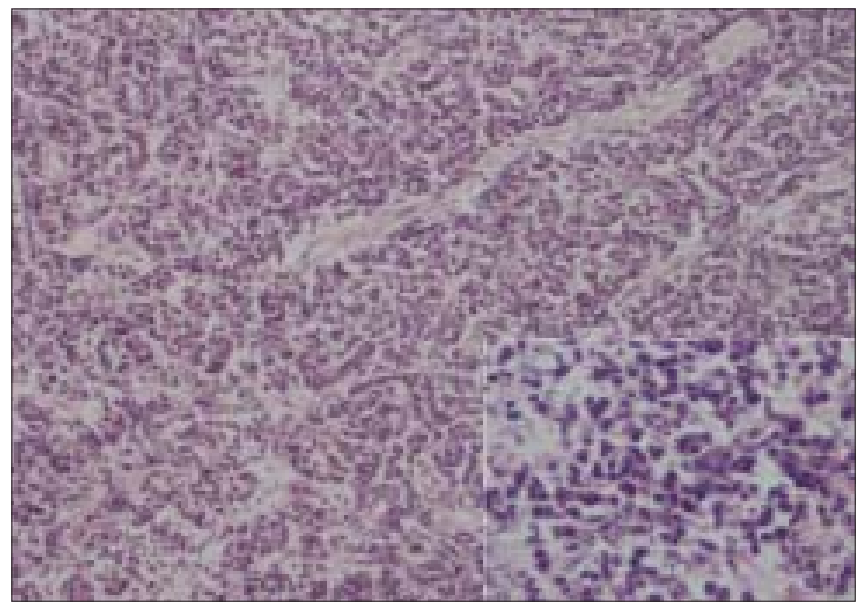

Figure 1: Non-Hodgkin's lymphoma showing monotonous population of lymphoid cells in diffuse sheets. H\&E x100. Inset higher magnification of the same. H\&E x200

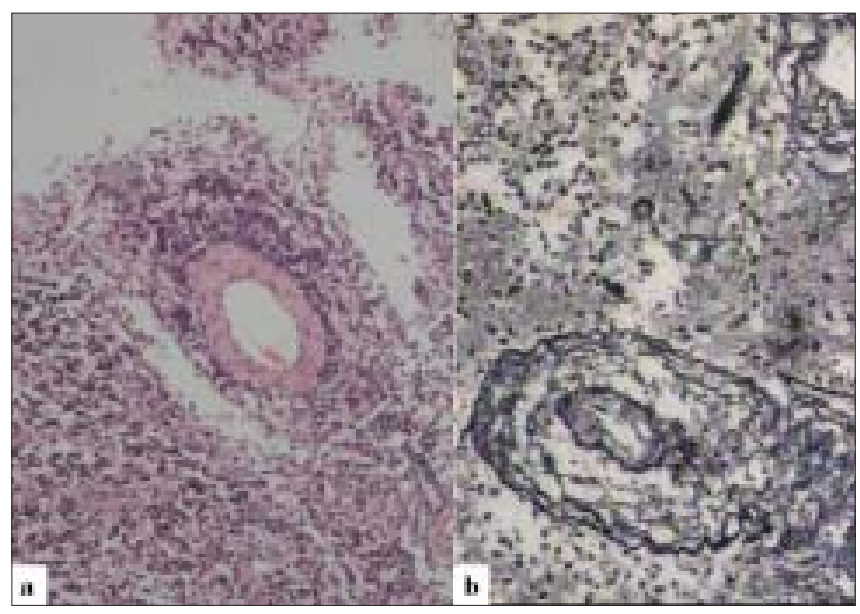

Figure 2: a) Angiocentric pattern of the lymphoid cells. H\&E x100. b) Splaying of the reticulin network around the vessel. Reticulin x100

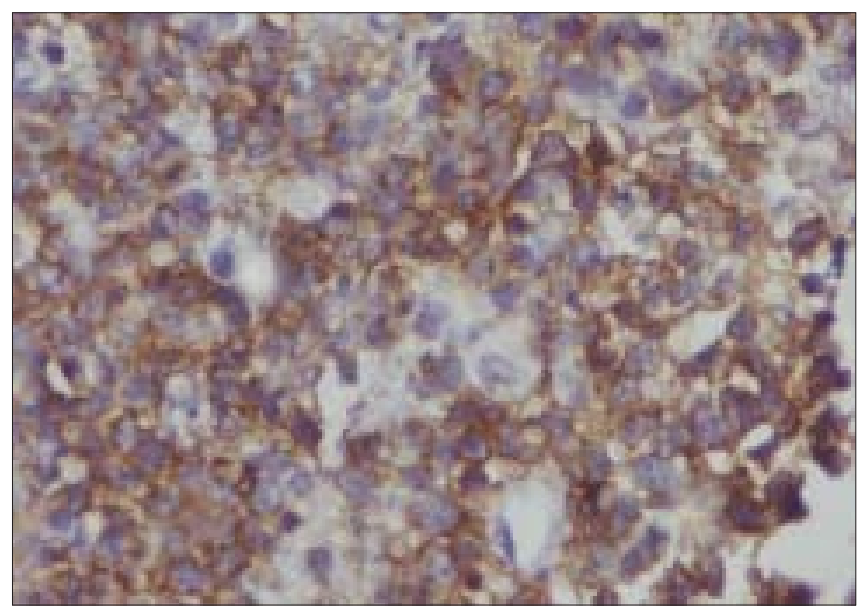

Figure 3: CD 20 showing characteristic membrane positivity in the lymphoid cells. Strept ABC x200

IH C was performed, whenever the blocks were available. The panel used when lymphomas were suspected were
LCA, CD 3 and CD 20. Leucocyte common antigen ( $L C A$ ) was strongly positive in 42 cases and weakly positive in 2 cases. The B-cell marker CD 20 was positive in $86 \%$ cases [Figure 3]. D ue to non-availability of the markers, further typing with CD 79a or PAX 5 for B-cell origin was not done. Three cases of B-cell lymphoma showed reactive $T$ - lymphocytes and one case was diagnosed as a T- cell lymphoma. This patient was a female, immunocompetent with a single lesion in the cerebellum.

IHC was performed with other markers when there was a differential diagnosis of lesions like metastasis, small cell glioblastoma and other round cell tumors. The other markers done which were negative, were epithelial membrane antigen (EMA)-3 cases, glial fibrillary acidic protein (GFAP) - 8 cases, and one case each of cytokeratin (CK), neuron specific enolase (NSE) and CD 99.

\section{Discussion}

The results of our findings were compared to other studies - western, Indian and from the far east and are shown in Table 6.

The incidence of PCNSLs in India seems to be fairly constant through the years, as seen in previous series ${ }^{[5,6]}$ as well as in the present study. In literature, the incidence varies in different time periods. O ne publication from Pakistan, ${ }^{[10]}$ which included both cranial and spinal lymphomas, reported that lymphomas accounted for $4.6 \%$ of intra-cranial and spinal neoplasia. There have been two large case-studies from Japan ${ }^{[1,12]}$ which reported that PCNSLs accounted for $2.4 \%$ of all intracranial neoplasms in Japan.

The male to female ratio is 1.5:1 in the present series, which is similar to most published series in immunocompetent patients. In patients with AIDS, the disease is much more common in males.

In the previous studies from India, ${ }^{[5,6]}$ majority of the PCN SL s have been reported in the immunocompetent. The present study has only one patient who was H IV positive (35 year old male). Sarkar et al,,5] had one H IV positive patient and one patient of renal allograft. Powari et $a l,{ }^{[6]}$ had two patients with renal allografts. In spite of an increasing number of H IV positive patients in India, the incidence of PCNSL s in these patients is low. A possible explanation for this could be that AIDS patients die earlier in India due to opportunistic infections. $^{[5]}$ Though other lymphomas, including those at extranodal sites seem to occur in India in patients with AIDS, PCN SLs are still infrequently reported. 


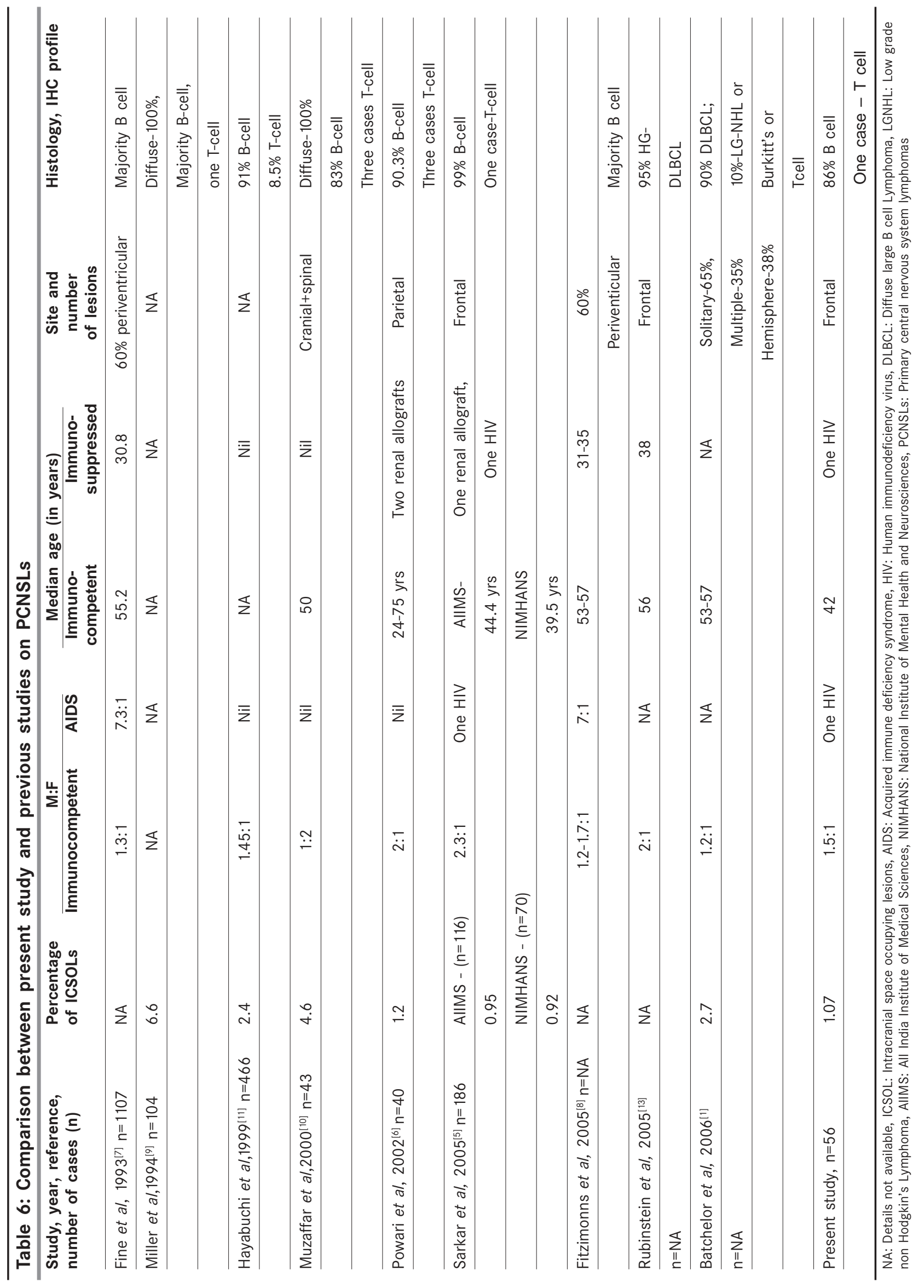


The median age of presentation is 42 years in immunocompetent, which is similar to those observed from India like - AlIM S (44.4 years) and NIMHANS (39.5 years). This is a whole decade earlier than those reported in the west. This has been attributed to the demographic pattern of the Indian population. ${ }^{[5]}$ The authors have also observed that other hematologic malignancies like multiple myeloma and chronic myeloid leukemia also present a decade or two earlier in India than in the west.

The most common presenting symptom was headache occurring in $57 \%$ patients. Seizures at presentation were seen in only $20 \%$ patients. This has been attributed to the fact that PCNSLs less often involve excitable cerebral cortex than other tumors do. ${ }^{[14]}$

In this study, majority of the lesions were in the supratentorial region with the frontal lobe being most commonly involved. This is similar to other studies. ${ }^{[5,13]}$

Of the 56 PCNSLs, 55 were diffuse large cell lymphomas and one was reported as Iymphoblastic. Virtually all PCNSLs show a diffuse growth pattern. A follicular growth pattern has not been described in intraparenchymal lesions. There have been occasional case reports of follicular lymphomas of the dura. ${ }^{[15,16]}$ These lesions have a less aggressive behavior and survive longer than the usual intraparenchymal PCNSLs.

Of the cases where immunohistochemistry was performed, $86 \%$ were classified as B-cell lymphomas. This is similar to reports, ${ }^{[1]}$ where $90 \%$ of the PCN SLs are diffuse large B-cell lymphomas. There was one case of T-cell lymphoma, which occurred in a 51-year-old female in the cerebellum. As per literature, ${ }^{[17]} \mathrm{T}$-cell lymphomas constitute only $2 \%$ of all PCNSLs, occur mainly in the immunocompetent, have a higher male to female ratio, are more frequent in the posterior fossa, mainly cerebellum, with a propensity to arise in the meninges. Studies from the east ${ }^{[11,18]}$ indicate that the incidence of T-cell lymphomas were high in Japan $(8.5 \%)$ as well as Korea (16.7\%). T-cell lymphomas have to be differentiated from T-cell rich B-cell lymphomas. There were three cases of B-cell lymphomas which had reactive $T$ lymphocytes, admixed with the tumor cells.

$M$ ajority of the patients were further evaluated for lymphadenopathy, organomegaly, and had a bone marrow evaluation to rule out secondary involvement by a systemic lymphoma. N one of the patients had marrow involvement at diagnosis. Following the diagnosis of $P C N S L$, the extent of staging required to evaluate for a systemic lymphoma is controversial. ${ }^{[1,8,19]}$ There are those who advocate that it is sufficient to perform a thorough clinical examination, complete blood counts, routine biochemical tests, serum LDH levels and chest radiographs; but there are others who recommend that the patients have contrast-enhanced CT scans of the chest, abdomen, pelvis as well as a bone marrow biopsy, given that $3.9-12.5 \%$ of patients with PCN SL s are found to have occult extra neural disease on additional evaluation.

Regarding prognosis, ${ }^{[20]}$ it is suggested that an age more than 60 years, performance status more than one, elevated LDH levels, high CSF proteins and involvement of deeper regions of the brain (periventricular, basal ganglia, brain stem and cerebellum) were significantly and independently associated with a worse survival.

The exact pathogenesis of PCNSLs in the immunocompetent is still not clear. Various theories of origin have been put forward. ${ }^{[7,17]}$

1) A polyclonal intracerebral inflammatory lesion may expand clonally in the brain and progress to a monoclonal neoplastic state. $\mathrm{H}$ owever, infection or inflammatory diseases have only exceptionally been described to antedate the development of PCNSL.

2) Lymphoma cells may be systematically eradicated by an intact immune system, but may be protected in an immunologically protected site like the brain. H owever, there is no evidence of concomitant lymphoma at other immunologically privileged sites like the testis.

3) B-cells may be transformed at a site elsewhere in the body and then develop adhesion molecules specific for cerebral endothelia. However, a study by Paulus et $a^{1},{ }^{[21]}$ showed that the expression pattern of a number of integrins and immunoglobulin adhesion molecules by tumor cells did not differ between cytologically similar PCNSLs and nodal lymphomas. It is possible that the responsible adhesion molecules were missed in the study or were down regulated by lymphoma cells, once they entered the brain.

Studies have shown a consistent association of tumors occurring in immunocompromised individuals with Ebstein Barr virus (EBV), suggesting an important role for the virus in the pathogenesis of these tumors. An infrequent association of the virus with PCNSL in the immunocompetent has also been noted. A study from India ${ }^{[22]}$ showed that immunocompetent individuals in developing countries are infrequently EBV associated and possibly a different pathogenetic mechanism is operational in the evolution of these tumors.

Systemic diffuse large B cell lymphomas (DLBCLs) 
are known to be clinically and morphologically heterogenous. They have recently been sub-classified as germinal centre $B$-cell origin (GCB) and nongerminal centre $B$-cell types using microarray. The germinal centre $B$-cell $D L B C L$ is associated with a better prognosis compared to non-germinal centre $B$ cell type. PCN SL s have a poorer prognosis when compared to other DLBCLs. Two studies ${ }^{[23,24]}$ using an extensive immunohistochemical panel including CD 10, BCL 6, BCL - 2, MUM 1, etc have shown that PCN SLs are more homogenous than systemic DLBCLs and predominantly express the activated $B$-cell line $(A B C)$ phenotype. This activated B-cell phenotype is thought to be responsible for the biologic aggressiveness and poor prognosis of PCNSL.

\section{Conclusion}

The present study, like other Indian studies, ${ }^{[5,6]}$ concludes that there has not been an increase in PCN SL $s$ in India. The PCN SLs tended to occur in young patients, and majority were diffuse large B cell lymphomas. Though there is an epidemic of HIV/AIDS in India, association of PCNSLs with HIV/AIDS is still low.

\section{References}

1. Batchelor T, Loeffler JS. Primary CNS Iymphoma. J Clin Oncol 2006;24:1281-8.

2. Traweek ST. Nervous system involvement by lymphoma, leukemia and other hematopoietic cell proliferations. In: Bigner DB, McLendon RE, Bruner JM, editors. Russell and Rubinstein's Pathology of Tumors of the Nervous System. $6^{\text {th }}$ ed. Arnold; 1998. p. 195-237.

3. Eby NL, Grufferman S, Flannely CM, Schold SC Jr, Vogel FS, Burger PC. Increasing inidence of primary brain lymphoma in the US. Cancer 1988;62:2461-5.

4. Kadan-Lottick NS, Skluzacek MC, Gurney JG. Decreasing incidence rates of primary central nervous lymphoma. Cancer 2002;95: 193-202.

5. Sarkar C, Sharma MC, Deb P, Singh R, Santosh V, Shankar SK. Primary central nervous system lymphoma: A hospital based study of incidence and Clinicopathological feature from India (1980 -2003). J Neurooncol 2005;71:199-204.

6. Powari M, Radotra B, Das A, Banerjee AK. A study of primary nervous system lymphoma in northern India. Surg Neurol 2002;57:113-6.

7. Fine HA, Mayer RJ. Primary central nervous system lymphoma. Ann Intern Med 1993;119:1093-104.

8. Fitzsimmons A, Upchurch K, Batchelor T. Clinical features and diagnosis of primary central nervous system lymphoma. Hematol Oncol Clin North Am 2005; 19:689-703.

9. Miller DC, Hochberg FH, Harris NL, Gruber ML, Louis DN, Cohen
H. Pathology with clinical correlations of primary central nervous system non-Hodgkin's lymphoma: The Massachusetts General Hospital experience 1958-1989. Cancer 1994;74:1383-97.

10. Muzaffar S, Siddiqui MS, Siddiqui I, Soomro IN, Pervez S, Kayani $\mathrm{N}$, et al. Central nervous system lymphomas: A histologic and immunophenotypic analysis. J Pak Med Assoc 2000;50:141-4.

11. Hayabuchi N, Shibamoto Y, Onizuka Y. Primary Central Nervous System Lymphoma in Japan: A nationwide Survey. Int J Radiation Oncol Biol Phys 1999;44:265-72.

12. Shibamoto Y, Tsuchida E, Seki K, Oya N, Hasegawa M, Toda Y, et al. Primary central nervous system lymphoma in Japan 1995-1999: changes from the preceding 10 years. J Cancer Res Clin Oncol 2004; 130:351-6.

13. Rubenstein JL, Treseler P, O'Brien JM. Pathology and genetics of primary central nervous system and intraocular lymphoma. Hematol Oncol Clin North Am 2005; 19:705-17.

14. Fine HA, Loeffler JS Primary central nervous system lymphoma. In: Canellos GB, Lister TA, Sklar JL, editors. The lymphomas. Philadelphia: WB Saunders; 1998. p. 481-94.

15. Hamilton DK, Bourne TD, Ahmed H, Cousar JB, Mandell JW, Sheehan JP. Follicular lymphoma of the dura: Case report. Neurosurgery 2006;59:E703-4.

16. Jahnke K, Theil E, Schilling A, Herrlinger U, Weller M, Coupland SE, et al. Low-grade primary central system lymphoma in immunocompetent patients. Br J Haematol 2005; 128:616-24.

17. Paulus W, Jellinger K, Morgello S, Deckert-Schluter M. Malignant lymphomas. In: Kleihues P, Cavenee WK,editors. World Health Classification of tumors, Pathology and Genetics Tumors of the nervous system. Lyon: TARC Press; 2000. p. 197-203.

18. Choi JS, Nam DH, Ko YH, Seo JW, Choi YL, Suh YL, et al. Primary central nervous system lymphoma in Korea: Comparison of B- and T-cell Lymphomas. Am J Surg Pathol 2003;27:919-28.

19. Abrey LE, Batchelor TT, Ferreri AJ, Gospodarowicz M, Pulczynski EJ, Zucca E, et al. Report of an international workshop to standardize baseline evaluation and response criteria for primary central nervous system lymphoma. J Clin Oncol 2005;23:5034-43.

20. Ferreri AJ, Blay JY, Reni M, Pasini F, Spina M, Ambrosetti A, et al. Prognostic scoring system for primary CNS lymphomas: The international extranodal lymphoma study group experience. J Clin Oncol 2003;21:266-72.

21. Paulus W, Jellinger K. Comparison of integrin adhesion molecules expressed by primary brain lymphomas and nodal lymphomas. Acta Neuropathol 1993;86:360-4.

22. Rao CR, Jain K, Bhatia K, Lakshmaiah KC, Shankar SK. Association of primary central nervous sytem lymphomas with the Ebstein-Barr virus. Neurol India 2003;51:237-40.

23. Camilleri-Broet S, Criniere E, Broet P, Delwail V, Mokhtari K, Moreau $\mathrm{A}$, et al. A uniform activated B-cell like immunophenotype might explain the poor prognosis of primary central nervous system lymphomas: Analysis of 83 cases. Blood 2006; 107: 190-6.

24. Bhagavathi S, Sharatkumar A, Hunter S, Sung L, Kanhere R, Venturina MD, et al. Activated B-cell immunophenotype might be associated with poor prognosis of primary central nervous system lymphomas. Clin Neuropathol 2008;27:13-20.

Source of Support: Nil, Conflict of Interest: None declared. 